\title{
A DESCRIPTIVE STUDY OF THE NUTRITION-RELATED CONCERNS OF CAREGIVERS OF PERSONS WITH DEMENTIA
}

\author{
J.G. Anderson, K.M. Rose, A.G. Taylor
}

\begin{abstract}
Objective: Family caregivers are the mainstay of caregiving support to persons with dementia, and often care for a family member with dementia for a decade or more prior to institutionalization or death. Malnutrition, including weight loss, is common among older adults with dementia, occurs throughout the disease process, and is associated with institutionalization and death. Nutrition education for caregivers is an important aspect of addressing the care needs of adults with dementia; however, nutrition education research in community-based persons and families experiencing dementia is minimal to non-existent. The need for tailored education resources ranks as highly important among caregivers; however, the nutrition concerns of caregivers in the home have not been identified. The purpose of the current study was to gather descriptive data about the nutrition-related concerns of family caregivers of persons with dementia. Design: A qualitative descriptive design using semi-structured interviews of caregivers of persons with dementia $(n=4)$ was used to collect the data. Thematic and content analysis was used. Results: Family caregivers experienced nutrition-related concerns and described a need for nutrition education to support the caregiving role. Four themes emerged: (1) meal preparation and food choices; (2) lack of appetite and eating behaviors; (3) making sense of existing nutrition information; (4) searching for reliable nutrition information. A discussion of each theme, including exemplars, is presented, along with suggestions provided by participants regarding how to address existing nutrition education resource needs. Conclusions: Issues surrounding care often are complex and require accurate and tailored information. Findings from the current study provide rich, valuable data regarding the needs of family caregivers with respect to nutrition concerns, allowing for the development, design, testing, and delivery of nutrition education resources and strategies.
\end{abstract}

Key words: Dementia, caregiving, nutrition education, eating behaviors.

\section{Introduction}

Over the past 50 years, the understanding of the impact of nutrition and dietary patterns on health has become increasingly important (1), facilitating a growing interest in the relationships between aging, nutrition, and cognition among both the public and researchers (2). Weight loss and malnutrition are common issues among older adults with dementia (3-6), occurring throughout the disease process and associated with death, muscle loss, loss of independence, and institutionalization (5, 7). Additionally, insufficient caloric intake is associated with reduced cognitive function, sleep disturbances, and fatigue $(8,9)$. Impaired nutritional status is associated with the severity of dementia, particularly the behavioral and psychological symptoms expressed by persons with dementia (10).

Department of Acute and Specialty Care, School of Nursing, University of Virginia, Charlottesville, Virginia, USA

Corresponding Author: Joel G. Anderson, PhD, CHTP, Department of Acute and Specialty Care, University of Virginia School of Nursing, P.O. Box 800782, Charlottesville, VA 22908-0782, Telephone: (434) 243-9936, Fax: (434) 243-9938, Email: jga3s@virginia.edu
Providing care for a family member with dementia is recognized as a chronically stressful situation that may have a negative impact on the mental and physical health of the caregiver (11). Being a caregiver is not only linked with high levels of burden, depression, and anxiety (12), but also has a potentially negative impact on the nutritional status of the caregiver (11). Nearly a quarter $(21 \%)$ of family caregivers of persons with dementia are at risk for malnutrition (13), and those with depressive symptoms are more likely to present with a poor nutrition status. Additionally, the nutritional status of the family member with dementia is inversely associated with the level of burden experienced by the caregiver (14).

The specific nutrition concerns and issues of caregivers in the home in the United States have not been identified. Given this fact, whether or not existing nutrition education resources adequately and accurately address the nutrition concerns of caregivers also is unknown. Studies are needed that identify topics and themes for potential interventions specific to caregiver needs and types, that incorporate data collection at sites convenient to the caregivers, and that are oriented toward 
Table 1

Interview questions and prompts

\begin{tabular}{ll}
\hline Semi-structured Interview Questions & Potential Interview Question Prompts \\
\hline $\begin{array}{l}\text { What sorts of problems or questions do you have regarding eating and nutrition for } \\
\text { your care recipient? }\end{array}$ & Appetite \\
What sorts of problems or questions do you have regarding nutrition for yourself? & Weight changes \\
What resources have you used to address these nutrition concerns? & Food preferences \\
Why do you use these resources? & Food safety \\
$\begin{array}{l}\text { Are you aware of other resources that you are currently not using? } \\
\text { Why do you choose not to use these resources? }\end{array}$ & Understanding nutritional needs \\
$\begin{array}{l}\text { What types of resources about nutrition would you like to have available for your care } \\
\text { recipient? }\end{array}$ & Fluid requirements \\
$\begin{array}{l}\text { What types of resources about nutrition would you like to have available for yourself? } \\
\text { What types of resource formats are you comfortable using? }\end{array}$ & Vitamins and supplements \\
$\begin{array}{l}\text { Any other suggestions you would like to make on nutrition education needs of caregi- } \\
\text { vers? }\end{array}$ & Inadequate nutrition resources \\
\hline
\end{tabular}

maintenance or improvement of dietary habits during the caregiving process to decrease the risk of chronic disease and reduce caregiver burden (15). Thus, the aim of the current study was to identify the nutrition-related concerns and topics important to informal caregivers of persons with dementia.

\section{Methods}

\section{Study Sample}

Participants were recruited using study flyers placed in aging care clinics, assisted living facilities, inpatient clinical areas, and Web advertisements. Eligibility criteria of potential participants included individuals who (a) self-identified as an unpaid, informal caregiver for a person with a physician-confirmed chronic, dementing illness per standard neurological criteria for dementia, (b) were 18 years of age or older, (c) were able to speak and understand English, and (d) were willing to engage in a 30-45 minute semi-structured interview. All aspects of the study were approved by the Institutional Review Board for Health Sciences Research.

\section{Interview Procedure}

Demographic information including age, marital/ partner status, education, ethnicity and race, income, employment status, and number of months in the caregiving role of the caregivers was obtained. A semistructured interview, lasting approximately 45 minutes, was conducted using an interview guide and prompts adapted from Keller et al. (5) (Table 1). Questions focused on nutrition and eating issues of both the care recipient and the caregiver. Interviews were conducted either in person or via telephone. Detailed notes were taken in addition to audio recordings; these recordings were transcribed in full for qualitative analysis.

\section{Data Analysis}

Transcripts from the interviews were analyzed separately and in aggregate to gain the unique perspective of each interview and the overall results. Data from the interviews were organized, analyzed, and interpreted using content analysis (16) and supplemented by a thematic analysis approach (17). Dedoose software was used for the data analysis, and codes were ascribed. The lead author (JGA) used the analysis steps delineated by Weber: review the narratives, define coding units, define categories, test coding, assess accuracy or reliability, and revise the coding rules and assess the accuracy (16). Codes were created based on the verbatim words used by the participants in the interview. Definitions for codes were described in a coding manual to help the research team remember the exact meanings of the existing codes whenever a new code was created. Memos included expression of thoughts in words, sentences, diagrams, and symbols. The maintenance of analytic memos throughout the data analysis process helped research team members to identify the categories and themes as these emerged from the analysis.

Transcripts were analyzed multiple times in different orders and also simultaneously after the initial analysis to ensure that no codes were missed. The research team met and compared the data analysis results, including the emerging codes and categories. Coding was initially completed by the lead author and categories developed. Other members of the research team were asked to 
review the narratives independently and review the categories. Research team members maintained memos to draft both thought processes and their own individual assumptions and biases. The codes were then organized into a broader classification of categories. The groups of codes that expressed the same ideas or phenomena were classified broadly into categories. Major themes evolved that subsumed all of the categories, the defining properties, and the interrelationships. The research team discussed findings and reached consensus surrounding the themes that emerged from the data.

\section{Results}

The sample $(\mathrm{N}=4)$ consisted of Caucasian caregivers ranging in age from 27 to 83 years. Two caregivers were the children of a person with dementia, one was a grandchild, and one was a spouse. The amount of time spent in the caregiving role ranged from 10 months to 10 years. Three caregivers lived with their care recipients while one provided care to a family member who resided in an assisted living facility. Family caregivers experienced nutrition-related concerns and described a need for nutrition education to support them in the caregiving role. Four overall themes emerged from the analysis: (1) meal preparation and food choices, (2) lack of appetite and eating behaviors, (3) making sense of existing nutrition information, and (4) searching for reliable nutrition information.

\section{Meal preparation and food choices}

Caregivers expressed concerns and issues related to the preparation of meals in the home, as well as food selection and food choices in the home, outside the home and, in one instance, assisted living facilities, which were described as "not so much focused on fresh fruits and vegetables." Participants related instances in which meal preparation and food choices led to experiences of stress and burden, as in the following exemplar:

"...there's this big stress about, 'Oh, what are we going to eat now.' And then it's like, 'Oh, we have to go the store for it.' It's not like... any sort of planned meals ahead of time. It's always like, "Okay, it's 12:00. We have to eat something. Let's go to fast food or something like that,» which...isn't...great obviously."

Additionally, because all of the caregivers were interested in providing their loved ones with nutritious food choices and options, this desire increased the stress and burden experienced by the caregivers. One participant stated:

"You've got to fix the meals for her...I don't go out and buy food at a restaurant cause [sic] I don't know what they're putting in it and I want to give her the healthiest options I can. So when I'm taking the food, I have to go do the shopping and then the preparation and then I take it over and then eat with her. So it's a much more involved process."

Caregivers also experienced stress when trying to engage a care recipient who at one time was the primary meal preparer for the family. Learning to step in the role and be more actively involved in meal preparation was a source of angst. One participant related the following:

"...one of the things that the women in my family prided themselves on was being good cooks. You know Southern cooking. It's...nurturing. It's...comforting. So at the early stages you know we still tried to say, 'hey, why don't you cook this?' And we would be kind of glancing to make sure that everything...wwas okay. But...[she] can't do that now."

\section{Lack of appetite and eating behaviors}

Caregivers spoke of issues related to feeding challenges, the most common being a lack of appetite. For instance, one participant stated that her family member with dementia was "... willing to eat what I put in front of her but there's...no active participation. She's not seeking anything." Participants described their care recipients as "distracted" at meal times. For example, one participant stated "I will prepare a meal that I think is nutritious but...[she] doesn't have the ability to sit still that long." Another noted "...we'll sit there for 10 [or] 15 minutes and then she'll want to get up."

With regard to a perceived lack of appetite, caregivers were frustrated by not knowing whether or not their loved one with dementia was simply not hungry or was unaware of their need or desire to eat. One participant stated "...she doesn't seem to be aware of whether or not she's hungry and she also doesn't take it upon herself to eat." Another said "...if you ask her if she's hungry, she'll ask someone else if they're hungry." This situation was described as "complex," with one participant stating "...I don't think [she] forgets to eat. But she does have to be prompted to eat."

These eating behaviors were a source of frustration for caregivers, who were unsure how to approach these issues to provide quality care for their loved one. One caregiver expressed their frustration saying, “... sometimes she says she's not hungry and...I know she hasn't eaten since the morning and it's like 5:00 [in the evening] or something." Caregivers were uncertain if they "should be sort of saying, 'Have you had three meals each day?'" or allow their care recipients to regulate meal times on their own. The level of uncertainty, frustration, and lack of knowledge related to whether or not their loved ones were capable of recognizing hunger is expressed in the following exemplar:

"[What is]...the best way to sort of handle that, whether or not it's okay to just say, 'Well, you need to eat something,' or to actually listen to her when she says she's not hungry,"

Caregivers also expressed concerns about their own 
health when dealing with erratic meal times, lack of appetite, and problematic eating behaviors that they experienced while caring for a family member with dementia, as depicted in the following:

"And also there's the appetite problem,...she doesn't want to eat and so in order to get her to eat, you have to eat with her. So, that's a problem for me because I don't eat that much. And when I do eat that much I gain weight and she wants me to be there eating the meals in the facility with her. And there is...nothing that they serve that I want to eat. But I've got to eat what she's eating... she even compares amounts. Like you're not eating as much as I'm eating."

\section{Making sense of existing nutrition information}

Caregivers were very much interested in accessing and making use of nutritional information. This desire was fuelled by the question expressed by each of them-"what should I really be doing?" However, the participants expressed difficulty not only in finding information, but also making sense of the information that they located, as in the following example:

“...I don't really ever get great answers. I sort of get mired in... what's going on or where's the reputable resource or where's...the current...information...It would be nice to know...that I could go to the Alzheimer's Association Web site and see...the general idea or consensus on a topic."

Additionally, caregivers were frustrated by a lack of synthesis regarding existing nutrition information and resources, as well as the response by health care professionals to their requests for more information, as expressed in the following:

"I think there is just such a body of knowledge that it's hard, nobody's been able to...really synthesize what's going on out there and new stuff keeps hitting the airways and so everybody is trying to digest it. And the answer of the health care provider seems to be a pill. And that has never been a favorite of mine. If you don't have anything else for me,...I don't have a lot of confidence in you as a health care provider if all you have to offer me is a pill."

\section{Searching for reliable nutrition information}

The desire to locate and use reliable nutrition information and resources was expressed by each of the caregivers. The impetus of this search was most often led by the participants' own interests in nutrition and providing nutritious, healthy food choices and meals that would enhance the health of their loved ones, potentially slowing the progression of the disease. One caregiver stated,

"I want to feed her and have her eat as healthy a diet as possible...if there was a way that I felt was possible to manipulate the diet to slow the [mental] decline, I would be interested in that. Or even to make her...clearer thinking, regardless of what level she's at. Those are the kinds of things I'm interested in."

Frequently, caregivers spoke of searching for resources that were "backed up by people who are experts in the field who should actually be able to interpret the results correctly of research studies." One caregiver stated, "I wish that there was something that I felt confident was... evidence-based."

In their efforts to uncover the sought after nutrition information and resources, caregivers described challenges in finding the information for which they were looking. One stated, “...I don't think I ever find like, 'oh, this is exactly what I was looking for. And this is the answer.' I think I spend a lot of time looking." Another caregiver expressed the following:

"I tend to find it difficult to find reputable sources... when you're just looking on the Internet, there's no clear indication that this is a worthwhile resource or... whether this study was...disproved like a month later or something."

The level of frustration can be best summed up by one caregiver who said, "...I haven't found anything... because I'm looking for the answer and nobody has the answer."

\section{Discussion}

In the current study the researchers identified four themes related to the nutrition concerns and issues experienced by caregivers of persons with dementia: (1) meal preparation and food choices, (2) lack of appetite and eating behaviors, (3) making sense of existing nutrition information, and (4) searching for reliable nutrition information. To the authors' knowledge, this is the first study to explore the nutrition-related concerns of the family caregivers of community dwelling adults with dementia conducted in the United States. The findings of the present study point to a need for tailored, evidencebased nutrition education resources for the family caregivers of persons with dementia.

As family members with dementia experience a continued loss of autonomy and cognitive decline, caregivers must deal with an increasing array of challenges, including those involved in managing the diet and food preparation of their loved one (18). Caregivers in the current study described modifications and concerns related to meal preparation and food choices. In previous studies, caregivers have listed changes in the food preferences, as well as the loss of autonomy in meal preparation and food choices, as the main dietary challenges involved in caring for a family member with dementia (19-23). As the disease progresses, this loss of autonomy, as well as difficulties related to feeding, may lead to a poorer nutrition status for the person with dementia (19). 
Informal family caregivers often have limited knowledge about the behavioral and psychological symptoms expressed by persons with dementia and may have difficulty interpreting behaviors, especially during mealtime (24). For example, Alzheimer's disease is typically associated with changes in episodic memory, including an inability on the part of the person with dementia to recall whether or not $\mathrm{s} /$ he has eaten. Caregivers in previous studies identified decreased food intake and a lack of appetite as dietary challenges experienced while caring for a family member with dementia (19-23). This decreased food intake concomitant with progression of the disease may result from poor appetite, as well as depressed mood (23). Over time, inadequate food can lead to malnutrition, weight loss, and increased risk of mortality (7).

Apathy is a behavioral and psychological symptom of dementia that has been shown to be particularly burdensome for caregivers (25). Apathy on the part of the person with dementia often leads to a lack of participation in activities of daily living, including mealtimes and eating, and may require more intensive stimulation and engagement from the family caregiver (14). Apathy could weaken emotional and social exchanges between the caregiver and care recipient during mealtimes, decreasing the psychosocial function of eating with others (26). This is important given than mealtime quality recognized as essential factor to improve nutritional status of persons with dementia (27).

Family caregivers have been shown to possess poor nutrition knowledge and to be able only to recognize signs of gross malnutrition in the care recipient (28). Participants taking part in a study examining a caregiver education intervention scored lower on pre-tests for modules related to nutrition (29). Thus, nutrition education of caregivers is a potentially important aspect of addressing the care needs of adults with dementia. However, nutrition education research in persons and families experiencing dementia in the community is scarce, with caregiver education most often focused on the disease process of $\mathrm{AD}$ and dementia or general issues associated with the care recipient (5). Thus, family caregivers have been neglected in nutrition research, policy, and practice (15). Caregivers may benefit from nutrition education by enhancing their ability to provide nutritionally adequate diets for their care recipients, as well as helping them maintain their own health and wellbeing (15). Nutrition-related chronic diseases associated with aging and that increase risk of $\mathrm{AD}$, including CVD, diabetes, pulmonary disease, and cancer, occur in up to $86 \%$ of adults $\geq 70$ years of age (15). This is significant given that more than $30 \%$ of caregivers for the elderly are, themselves, age 65 years or older (30).

Many caregivers have cited a critical need for information (31) and identified educational support to be of more importance than additional task-oriented assistance (32). The need for tailored education resources ranks as highly important among caregivers, particularly in rural communities (31-36). Caregivers in international studies have indicated the need for nutrition education information specifically. In a Japanese survey study, Hirakawa and colleagues (37) found that almost 50\% of respondents were interested in specific and tailored food and nutrition information, finding that an overabundance of such information can be overwhelming and complicate the care process. In a Swedish study (6), spousal caregivers expressed concerns about how they struggled "to be a good food provider in everyday life" as a result of changing food preparation roles and coping with becoming a caregiver. The participants expressed concerns of gaps between available nutrition education resources and the quality of information presented (6).

The most common sources of information for family caregivers of individuals with $\mathrm{AD}$ and dementia include the Alzheimer's Association, allied healthcare professionals, family members, friends, clergy, and support groups (35). A previous study by Keller and colleagues (5) evaluating printed nutrition education resources provided by dementia society chapters found the need for development of better resources. In a recent study, half of the caregivers in the sample expressed interest in engaging in a nutrition education program (23). These same caregivers provided potential motivators for encouraging caregivers to take part in nutrition education programs, including the ability to feed and care adequately for a loved one with dementia, to learn more about nutrition, and to provide motivation for caregivers themselves to improve their eating habits (23).

Limitations of this study relate to the small sample size, which limits generalizability. However, while there were only four participants in the current study, saturation was reached with regard to the primary research question. Moreover, theoretical saturation in similar studies was achieved generally within in six interviews (38).

Issues surrounding care often are complex and require accurate and tailored information. By collecting descriptive data about caregiver needs, assessing current nutrition education resources, and critically examining the current evidence base, themes, and knowledge gaps can be identified. This study took a holistic approach to evaluating the problem and the findings provide information for future studies aimed at designing, testing, and disseminating new nutrition education materials tailored specifically to caregiver needs that address existing gaps in education resources while providing the most currently available evidence-based knowledge and dietary recommendations.

Conflict of interest: The authors have no conflicts of interest..

Ethical standard: The study was approved by the university's Institutional Review Board. 


\section{References}

1. Berger MM. Can oxidative damage be treated nutritionally? Clin Nutr 2005;24, 172-183.

2. Stewart R, Sabbah W, Tsakos G, D'Aiuto F, Watt RG. Oral health and cognitive function in the Third National Health and Nutrition Examination Survey (NHANES III). Psychosom Med 2008;70, 936-941.

3. White H, Pieper C, Schmader K, Fillenbaum G. Weight change in Alzheimer's disease. J Am Geriatr Soc 1996;44(3):265-272.

4. Vellas B, Lauque S, Gillette-Guyonnet S, Andrieu S, Cortes F, Nourhashem F, Cantet C, Ousset PJ, Grandjean H, REAL.FR Group. Impact of nutritional status on the evolution of Alzheimer's disease and on response to acetylcholinesterase inhibitor treatment. J Nutr Health Aging 2005;9, 75-80.

5. Keller HH, Smith D, Kasdorf C, Dupuis S, Martin LS, Edward G, Cook C, Genoe R. Nutrition education needs and resources for dementia care in the community. Am J Alz Dis Other Dem 2008;23, 13-22.

6. Fjellström C, Starkenberg Å, Wesslén A, Licentiate MS, Tysén Bäckström AC, Faxén-Irving G, The OmegAD Study Group. To be a good food provider: An exploratory study among spouses of persons with Alzheimer's disease. Am J Alz Dis Other Dem 2010;25, 521-526.

7. White H, Pieper C, Schmader K. The association of weight change in Alzheimer's disease with severity of disease and mortality: a longitudinal analysis. J Am Geriatr Soc 1998;46:1223-1227.

8. Morley JE. Nutrition and the brain. Clin Geriatr Med 2010;26, 89-98.

9. Soto ME, Secher M, Gillette-Guyonnet S, Abellan van Kan G, Andrieu S, Nourhashemi F, Rolland Y, Vellas B. Weight loss and rapid cognitive decline in community-dwelling patients with Alzheimer's disease. J Alz Dis 2012;28, 647-654.

10. Rullier L, Lagarde A, Bouisson J, Bergua V, Barberger-Gateau P. Nutritional status of community-dwelling older people with dementia: associations with individual and family caregivers' characteristics. Int J Geriatr Psychiatry 2013;28, 580-588.

11. Vitaliano PP, Zhang J, Scanlan J. Is caregiving hazardous to one's physical health? A meta-analysis. Psychol Bull 2003;129, 946-972.

12. Schulz R, O'Brien AT, Bookwala J, Fleissner K. Psychiatric and physical morbidity effects of dementia caregiving: prevalence, correlates, and causes. Gerontologist 1995;35, 771-791.

13. Torres SJ, McCabe M, Nowson CA. Depression, nutritional risk and eating behavior in older caregivers. J Nutr Health Aging 2010;14, 442-448.

14. Rullier L, Lagarde A, Bouisson J, Bergua V, Torres M, Barberger-Gateau P. Psychosocial correlates of nutritional status of family caregivers of persons with dementia. Int Psychogeriatr 22014;6, 105-113.

15. Silver HJ, Wellman NS. Nutrition education may reduce burden in family caregivers of older adults. J Nutr Educ Behav 2002;34, S53-S58.

16. Weber RP. Basic Content Analysis. Newbury Park, CA: Sage Publications, 1990.

17. Vaismoradi M, Turunen H, Bondas T. Content analysis and thematic analysis: implications for conducting a qualitative descriptive study. Nurs Health Sci 15, 398-405.

18. Blennow K2013; de Leon MJ, Zetterberg H. Alzheimer's disease. Lancet 368, 387-403
19. Ikeda M, Brown J, Holland AJ, Fukuhara R, Hodges JR. Changes in appetite, food preference, and eating habits in frontotemporal dementia and Alzheimer's disease. J Neurol Neurosurg Psych 2002;73, 371-376.

20. Rivière $S$, Gillette-Guyonnet $S$, Andrieu $S$, Nourhashemi F, Lauque S, Cantet C, Salva A, Frisoni G, Vellas B. Cognitive function and caregiver burden: predictive factors for eating behaviour disorders in Alzheimer's disease. Int J Geriatr Psychiatry 2002;17, 950-955.

21. Holm B, Soderhamn O. Factors associated with nutritional status in a group of people in an early stage of dementia. Clin Nutr 2003;22, 385-389.

22. Keller HH, Edward G, Cook C. Mealtime experiences of families with dementia. Am J Alz Dis Other Dem 2007;21, 431-438.

23. Silva P, Kergoat MJ, Shatenstein B. Challenges in managing the diet of older adults with early-stage Alzheimer dementia: a caregiver perspective. J Nutr Health Aging 2013;17, 142-147.

24. Mamhidir AG, Karlsson I, Norberg A, Kihlgren M. Weight increase in patients with dementia, and alteration in meal routines and meal environment after integrity promoting care. J Clin Nurs 2007;16, 98-996.

25. Thomas P, Clement JP, Hazif-Thomas C, Léger JM. Family, Alzheimer's disease and negative symptoms. Int J Geriatr Psychiatry 2001;17, 1034-1047.

26. Keller HH, Martin LS, Dupuis S, Genoe R, Edward HG, Cassolato C. Mealtimes and being connected in the community-based dementia context. Dementia 2010;9, 191-213.

27. Aselage MB, Amella EJ. An evolutionary analysis of mealtime difficulties in older adults with dementia. J Clin Nurs 2010;19, 33-41.

28. Ryan C. Caregivers of the elderly: Lack of nutrition knowledge. J Nutr Elderly 1997;17, 35-44.

29. DiZazzo-Miller R, Samuel PS, Barnas JM, Welker KM. Addressing everyday challenges: feasibility of a family caregiver training program for people with dementia. Am J Occupat Ther 2014;68, 212-220.

30. U.S. Department of Health and Human Services. Alzheimer's disease, unraveling the mystery. NIH Publication Number 2008;08-3782: 4-5, 54.

31. Fortinsky R, Hathaway T. Information and service needs among active and former family caregivers of persons with Alzheimer's disease. Gerontologist 1990;30, 604-609.

32. Francis GM, Munjas BA. Needs of family caregivers and persons with Alzheimer's disease. Am J Alz Care Res 1992;7, 23-31.

33. Bowd A, Loos C. Needs, morale and coping strategies of caregivers for persons with Alzheimer's disease in isolated communities in Canada. Am J Alz Dis 1996;11, 32-39.

34. Beisecker AE, Chrisman SK, Wright LJ. Perceptions of family caregivers of persons with Alzheimer's disease: Communication with physicians. Am J Alz Dis 1997;12, 73-83.

35. Wackerbarth SB, Johnson MMS. Essential information and support needs of family caregivers. Patient Educ Counsel 2002;47, 95-100.

36. Edelman P, Kuhn D, Fulton BR, Kyrouac GA. Information and service needs of personas with Alzheimer's disease and their family caregivers living in rural communities. Am J Alz Dis Other Dem 2006;21:226-233.

37. Hirakawa Y, Kuzuya M, Enoki H, Uemura K. Information needs and sources of family caregivers of home elderly patients. Arch Gerontol Geriatr 2011;52, 202-205.

38. Guest G, Bunce A, Johnson L. How many interviews are enough? An experiment with data saturation and variability. Field Methods 2006;18, 5-82. 